\title{
Gene expression analysis of growth factor receptors in human chondrocytes in monolayer and 3D pellet cultures
}

\author{
ANIKA WITT $^{1}$, ACHIM SALAMON ${ }^{2}$, DIANA BOY $^{3}$, DORIS HANSMANN $^{1}$, ANDREAS BÜTTNER $^{3}$, \\ ANDREAS WREE $^{4}$, RAINER BADER ${ }^{1}$ and ANIKA JONITZ-HEINCKE ${ }^{1}$
}

\footnotetext{
${ }^{1}$ Department of Orthopaedics, Biomechanics and Implant Technology Research Laboratory, ${ }^{2}$ Department of Cell Biology, ${ }^{3}$ Institutes of Forensic Medicine and ${ }^{4}$ Anatomy, University Medical Centre Rostock, D-18057 Rostock, Germany
}

Received December 2, 2016; Accepted April 10, 2017

DOI: $10.3892 /$ ijmm.2017.2994

\begin{abstract}
The main goal of cartilage repair is to create functional tissue by enhancing the in vitro conditions to more physiological in vivo conditions. Chondrogenic growth factors play an important role in influencing cartilage homeostasis. Insulin-like growth factor (IGF)-1 and transforming growth factor (TGF)- $\beta 1$ affect the expression of collagen type II (Col2) and glycosaminoglycans (GAGs) and, therefore, the targeted use of growth factors could make chondrogenic redifferentiation more efficient. In the present study, human chondrocytes were postmortally isolated from healthy articular cartilage and cultivated as monolayer or 3D pellet cultures either under normoxia or hypoxia and stimulated with IGF-1 and/or TGF- $\beta 1$ to compare the impact of the different growth factors. The mRNA levels of the specific receptors (IGFIR, TGFBRI, $T G F B R 2$ ) were analyzed at different time points. Moreover, gene expression rates of collagen type 1 and 2 in pellet cultures were observed over a period of 5 weeks. Additionally, hyaline-like Col2 protein and sulphated GAG (sGAG) levels were quantified. Stimulation with IGF-1 resulted in an enhanced expression of $I G F I R$ and $T G F B R 2$ whereas TGF- $\beta 1$ stimulated $T G F B R 1$ in the monolayer and pellet cultures. In monolayer, the differences reached levels of significance. This effect was more pronounced under hypoxic culture conditions. In pellet cultures, increased amounts of $\mathrm{Col} 2$ protein and sGAGs after incubation with TGF- $\beta 1$ and/or IGF-1 were validated. In summary, constructing a gene expression profile regarding mRNA levels of specific growth factor receptors in monolayer cultures could be helpful for a targeted application of growth factors in cartilage tissue engineering.
\end{abstract}

Correspondence to: Dr Anika Jonitz-Heincke, Department of Orthopaedics, Biomechanics and Implant Technology Research Laboratory, University Medical Centre Rostock, 142 Doberaner Strasse, D-18057 Rostock, Germany

E-mail: anika.jonitz-heincke@med.uni-rostock

Key words: chondrocytes, chondrogenic redifferentiation, growth factors, receptors, pellet culture, oxygen

\section{Introduction}

Human articular cartilage tissue is characterized by a rich extracellular matrix (ECM) and a low cell density. The few chondrocytes are embedded in the ECM which is produced and retained by the former (1). Characteristic components of the ECM are collagen fibrils of collagen type II (Col2) and the proteoglycans aggrecan and chondroitin sulphate, and sulphated glycosaminoglycans (sGAG) (2).

Control of the chondrocytic phenotype within the physiological microenvironment is the main challenge in cartilage tissue engineering and cartilage repair (3). A current strategy in orthopedic surgery is autologous chondrocyte transplantation (ACT) and its advancements. In this two-step procedure, chondrocytic cells are isolated from an unaffected part of the patient's articular knee, expanded in monolayer cell culture, and finally implanted in the cartilage lesion. The implantation of the autologous cells can be carried out either with biomaterial constructs, or as suspension or 3D spheroid cultures without the use of biomaterials. For the phenotypical appearance and function of chondrocytes, the microenvironment of the cartilage tissue is substantial (4). Although the technique of ACT opens up new regenerative opportunities, this therapeutic approach is limited by the availability of unaffected cells (5) as well as their dedifferentiation potential to fibroblasts during in vitro expansion. This dedifferentiation process is characterized by an increased expression of characteristically fibrogenous proteins such as type I collagen (Col1) whereas cartilage-specific markers, such as collagen types II, XI, IX and proteoglycans like aggrecan (ACAN) are decreased (6,7). Fibroblastic cells are not capable to assemble an ECM which resists the mechanical forces within the joint.

An enhanced approximation of in vitro conditions to physiological conditions, such as culturing in $3 \mathrm{D}$ or reduced oxygen condition appears to promote the process of redifferentiation of the cells into a cartilaginous phenotype $(3,8)$. For this reason, the further development of the in vitro cultivation of chondrocytic cells in 3D could be beneficial, since spheroid cultures should sustain the chondrocytic phenotype during the process of ACT (9). Nevertheless, the balance between production and availability of essential growth factors for cartilage formation should not be neglected. Since growth factors are stored in the ECM and are released under specific 
conditions to regulate cellular behaviour (10), the isolation of chondrocytic cells from their natural environment reduces the availability of these growth factors. Exogenous growth factors are able to induce the formation of cartilage-like tissue $(7,11)$. Therefore, knowledge concerning the interaction of specific growth factors for cartilage regeneration is a prerequisite for high-quality hyaline cartilage.

Chondrogenic growth factors such as the insulin-like growth factor (IGF)-1 and transforming growth factor (TGF)- $\beta 1$ are able to influence the expression of Col 2 and GAGs within the cartilage tissue and thus influence chondrogenic redifferentiation (12). IGF-1 is an important anabolic factor for the stimulation of chondrocyte proliferation and matrix synthesis (13-15). Its activity is mediated via membranous IGF-1 receptors (IGFR1) (16).

TGF- $\beta 1$ is known to be an important stimulator of proteoglycans and Col2 synthesis in chondrocytes (17-19) and is able to induce the chondrogenic differentiation of mesenchymal stem cells in vitro (8). Effects emerging from TGF- $\beta 1$ are carried out via TGF- $\beta$ receptors existing as homodimeric or heterodimeric isoforms. Signals are transmitted by forming complexes consisting of dimers of TGF- $\beta$ receptor 1 (TGFBRI) and 2 (TGFBR2) $(20,21)$.

In previous studies, we showed that the addition of the chondrogenic growth factors TGF- $\beta 1$ and IGF-1 can influence chondrogenic redifferentiation in 3D cultures of alginate, spheroid and matrix-associated cultures (22-24). Moreover, we demonstrated that reduction of the oxygen content to more physiological conditions (5\%, hypoxia) improved the effects of growth factors on the redifferentiation process, especially for IGF-1 (22). In the present study, it was assumed that the reduced IGF-1 activity in chondrocytes under normoxia resulted from the enrichment of reactive oxygen species (22). Nevertheless, we observed donor-specific reactions on growth factor treatment, suggesting donor-specific expression profiles of IGF- 1 and TGF- $\beta$ receptors on chondrocytic cells. Therefore, the aim of the present study was to evaluate IGF- 1 and TGF- $\beta$ receptor mRNA expression levels in human chondrocytes in monolayer and 3D pellet cultures. A comparison of monolayer and pellet cultures should clarify whether a gene expression profile is suitable for therapeutic strategies and what type of cultivation is more effective. Doing this, we hypothesized that a targeted application of chondrogenic growth factors could improve cartilage tissue engineering strategies to optimize repair techniques such as ACT. Hence, we analyzed the impact of IGF- 1 and TGF- $\beta 1$ as well as a combination of both on the gene expression rates of collagen type I $\alpha \mathrm{I}(C O L 1 A 1)$, type II (COL2A1), as well as alkaline phosphatase $(A L P)$ and collagen type $\mathrm{X} \alpha \mathrm{I}(C O L 10 A 1)$ as hypertrophic markers in pellet cultures over a period of 5 weeks. Additionally, amounts of Col 2 protein as well as GAGs were quantified. We also examined the reduction of the oxygen content during cultivation with respect to the effect of different growth factors on chondrogenic cell behaviour.

\section{Materials and methods}

Isolation and cultivation of human chondrocytes. Human primary chondrocytes (female: $n=3$, age $36-44$ years; male: $n=2$, age 44-47 years) were isolated post mortem from unaf-
Table I. Three different growth factor combinations in the cell medium.

\begin{tabular}{lccc}
\hline & Combination 1 & Combination 2 & Combination 3 \\
\hline TGF- $\beta 1$ & $50 \mathrm{ng} / \mathrm{ml}$ & - & $50 \mathrm{ng} / \mathrm{ml}$ \\
IGF-1 & - & $50 \mathrm{ng} / \mathrm{ml}$ & $50 \mathrm{ng} / \mathrm{ml}$
\end{tabular}

TGF- $\beta 1$, transforming growth factor- $\beta 1$; IGF-1, insulin-like growth factor-1.

fected articular knee cartilage within 24 h to 6 days of death. All tissues did not show any signs of osteoarthritis or degeneration which was examined macroscopically. Isolation of cells was performed as described in the protocol of Jonitz et al (22). Cells were separated into two groups: i) hypoxia $\left(5 \% \mathrm{O}_{2}\right)$ and ii) normoxia $\left(21 \% \mathrm{O}_{2}\right)$ and incubated in a humidified atmosphere at $37^{\circ} \mathrm{C}$ in $5 \% \mathrm{CO}_{2}$. The tissue removal was approved by the Local Ethics Committee (registration no. A2011-138).

Stimulation of monolayer culture with chondrogenic growth factors. In passage three, chondrocytes were transferred to 48-well plates with 10,000 cells/well in Dulbecco's modified Eagle's medium (DMEM) containing $10 \%$ fetal calf serum (FCS), $1 \%$ penicillin/streptomycin, $1 \%$ amphotericin B (all from Invitrogen, Darmstadt, Germany) and ascorbic acid (final concentration, $50 \mu \mathrm{g} / \mathrm{ml}$; Sigma, St. Louis, MO, USA).

After $24 \mathrm{~h}$ of adherence under the described conditions (normoxia and hypoxia), the medium was replaced by serum-free medium containing ascorbic acid (final concentration: $50 \mu \mathrm{g} / \mathrm{ml}$; Sigma), dexamethasone (final concentration, $100 \mathrm{nM}$; Sigma), ITS ${ }^{\mathrm{TM}}$ (complete medium and ITS $^{\mathrm{TM}}$ in a 100:1 ratio; Becton-Dickinson, Heidelberg, Germany) and chondrogenic growth factors, IGF-1 (R\&D Systems, Wiesbaden, Germany) and/or TGF- $\beta 1$ (Tebu-Bio, Offenbach, Germany) in three different combinations (Table I). The chosen growth factor concentrations are based on previous studies (22-24). The stimulation was performed in duplicates, at $37^{\circ} \mathrm{C}$ in a humidified atmosphere of $5 \% \mathrm{CO}_{2}$ and the appropriate oxygen concentration for 24,48 and $72 \mathrm{~h}$, respectively. The beginning of the chondrogenic stimulation was defined as time point 0 .

Stimulation of pellet culture with chondrogenic growth factors. From 3 of the 5 donors, the stimulation was additionally performed as 3D pellet cultures. For pellet formation, $5 \times 10^{4}$ cells/well (passage three) were transferred into 96-well V-bottom suspension-plates suspended in the same three medium combinations as mentioned above (Table I). After centrifugation at $400 \mathrm{x}$ g for $5 \mathrm{~min}$ for sedimentation, the cells were incubated for $24,48,72 \mathrm{~h}$ as well as 14 and 35 days under standard culture conditions and a 5 or $21 \%$ oxygen level, respectively. The medium was changed every 2-3 days. For the start point (named as 0 ) $5 \times 10^{4}$ cells suspended in serum-free medium with ITS were used and the same pellet formatting procedure was used as described above.

RNA extraction and cDNA synthesis. For RNA isolation, the monolayer cells were directly lysed in the well. Pellet cultures 
Table II. cDNA primers for qPCR.

\begin{tabular}{|c|c|}
\hline Primer & $\begin{array}{c}\text { Sequence } 5^{\prime} \rightarrow 3^{\prime} \\
\text { (forward and reverse) }\end{array}$ \\
\hline$A L P$ & $\begin{array}{l}\text { CATTGTGACCACCACGAGAG } \\
\text { CCATGATCACGTCAATGTCC }\end{array}$ \\
\hline COL1A1 & $\begin{array}{l}\text { ACGAAGACATCCCACCAATC } \\
\text { AGATCACGTCATCGCACAAC }\end{array}$ \\
\hline COL2Al & $\begin{array}{l}\text { AATGGTGGCTTCCATTTCAG } \\
\text { GTGATGTTCTGGGAGCCTTC }\end{array}$ \\
\hline COL10A1 & $\begin{array}{l}\text { GAACTCCCAGCACGCAGAATC } \\
\text { AGTGGGCCTTTTATGCCTGT }\end{array}$ \\
\hline$I G F 1 R$ & $\begin{array}{l}\text { CGAGTGGAGAAATCTGCGGG } \\
\text { ACTCGGTAATGACCGTGAGC }\end{array}$ \\
\hline$T G F B R 1$ & $\begin{array}{l}\text { TTCCAACTACTGGTTTACCATTGC } \\
\text { AATCTCTGCCTCACGGAACC }\end{array}$ \\
\hline$T G F B R 2$ & $\begin{array}{l}\text { GTCACTGACAACAACGGTGC } \\
\text { TCTTTCTCCATACAGCCACACAG }\end{array}$ \\
\hline ACTB & $\begin{array}{l}\text { CTTCCTGGGCATGGAGTC } \\
\text { AGCACTGTGTTGGCGTACAG }\end{array}$ \\
\hline
\end{tabular}

$A L P$, alkaline phosphatase; $C O L 1 A 1$, collagen type $\alpha 1 ; C O L 2 A 1$, collagen type $2 \alpha 1$; COL10A1, collagen type $10 \alpha 1 ;$ IGF1R, insulin-like growth factor receptor 1 ; TGFBR1, transforming growth factor receptor $1 ; T G F B R 2$, transforming growth factor receptor $2 ; A C T B$, $\beta$-actin.

were transferred with lysis buffer into $2 \mathrm{ml}$ homogenisation tubes containing small steel beads (Precellys-Steel kit, $2.8 \mathrm{~mm}$; PeqLab Biotechnology GmbH, Erlangen, Germany) and homogenized for $30 \mathrm{sec}$ at $5,000 \mathrm{xg}$.

Isolation of RNA was performed using the peqGOLD Total RNA kit (PeqLab Biotechnology GmbH) which relies on the principle of column purification of RNA probes according to the supplier's recommendations.

For cDNA synthesis, the High Capacity cDNA kit (Applied Biosystems, Foster City, CA, USA) was used. An amount of $10 \mathrm{ng}$ isolated RNA of each sample was used and operated according to the manufacturer's instructions.

Quantitative (real-time) PCR ( $q P C R)$. Relative quantification of target cDNA levels was performed by qPCR (qTower 2.0; Analytik Jena AG, Jena, Germany) using the InnuMIX qPCR MasterMix SyGreen (Analytik Jena AG) and the cDNA primers (Sigma-Aldrich) which are listed in Table II. PCR was performed following the manufacturer's instructions undergoing the following process: $95^{\circ} \mathrm{C}$ for 2 min, 40 cycles of $95^{\circ} \mathrm{C}$ for $5 \mathrm{sec}$ and $65^{\circ} \mathrm{C}$ for $25 \mathrm{sec}$. The reactions were performed as duplicates.

For further analyses the $\Delta \Delta \mathrm{Cq}$ method was applied. The relative expression of each mRNA compared to the housekeeper $\beta$-actin was calculated according to the equation: $\Delta \mathrm{Cq}=\mathrm{Cq}_{\mathrm{target}}-\mathrm{Cq}_{\beta \text {-actin }}$.

The relative amount of target mRNA at each time point $(24,48,72 \mathrm{~h}$ and at 14 and 35 days) was normalized to the
mRNA level of unstimulated cells at time point 0 using the equation $\Delta \Delta \mathrm{Cq}_{\text {stimulation }}=\Delta \mathrm{Cq}_{\text {gene }}-\Delta \mathrm{Cq}_{\text {control }}$. The resulting gene expression is presented as the $2^{-\Delta \Delta C q}$ value.

The gene expression of the following chondrogenic marker genes was analyzed: $C O L 1 A 1$ and $C O L 2 A 1$, IGF-1-receptor $(I G F 1 R)$, TGF- $\beta$-receptor 1 and 2 (TGFBRI/TGFBR2). Furthermore, gene expression of $A L P$ and collagen type $\mathrm{X} \alpha 1$ (COL10Al) was determined to detect cell hypertrophy. Each gene was analyzed in duplicates.

Pro-Col2 quantification. Protein amounts of Col2 synthesized by chondrocytic pellet cultures were analyzed using an ELISA (Ibex Pharmaceuticals, Inc., Mont-Royal, QC, Canada). The principal of the ELISA is based on the cleavage of the carboxy propeptides of newly formed collagen which were measured in the supernatant of pellet cultures. Hence, supernatants of every medium combination from pellet cultures were collected after $24,48,72 \mathrm{~h}$ as well as after 14 and 35 days of incubation and stored at $-20^{\circ} \mathrm{C}$. The ELISA was performed according to the manufacturer's instructions. Absorbance was measured at $450 \mathrm{~nm}$ using Opsys $\mathrm{MR}^{\mathrm{TM}}$ microplate reader (Dynex Technologies, Denkendorf, Germany). The content of Col2 was normalized to the total protein content (ng Col2/mg protein ${ }_{\text {total }}$ ).

Total protein determination. Total protein content of the collected supernatants was determined using the Qubit ${ }^{\circledR}$ protein assay kit (Thermo Fisher Scientific, Waltham, MA, USA) following the manufacturer's instructions manual. Protein content was calculated using a defined standard curve. The supernatants of each pellet culture at every time point were collected and stored at $-20^{\circ} \mathrm{C}$. A cell-free medium combination incubated for 3 days served as background control.

Blyscan $^{T M}$ GAG assay. The Blyscan ${ }^{\mathrm{TM}}$ assay (Biocolor Ltd., Carrickfergus, Northern Ireland, UK) is a quantitative dye-binding method used to measure sulfated proteoglycans and GAGs. The supernatants of the stimulated pellet cultures were collected after $24,48,72 \mathrm{~h}$ as well as 14 and 35 days. After papain digestion at $60^{\circ} \mathrm{C}$ overnight (20 units $/ \mathrm{mg}$ papain from papaya latex; Sigma-Aldrich) in $50 \mathrm{mM}$ phosphate buffer [1 M $\mathrm{NaCl}, 5 \mathrm{mM}$ cystein-HCL, $1 \mathrm{mM}$ EDTA (Merck Millipore, Darmstadt, Germany)] the Blyscan ${ }^{\mathrm{TM}}$ assay was performed according to the manufacturer's instructions. Absorbance was measured at $656 \mathrm{~nm}$ using the Opsys microplate reader (Dynex Technologies). The content of sGAG was normalized to total protein content $\left(\mu \mathrm{g} \mathrm{sGAG} / \mathrm{mg}\right.$ protein $\left.{ }_{\text {total }}\right)$.

Histology. For histological investigations, human chondrocytes were cultured as pellet cultures and stimulated with TGF- $\beta 1$ and/or IGF-1 either under normoxia or hypoxia. After 35 days of incubation, the pellet cultures were embedded in Tissue-Tek ${ }^{\circledR}$ O.C.T. ${ }^{\mathrm{TM}}$ compound, stored at $-80^{\circ} \mathrm{C}$ and afterwards sectioned to $7-10 \mu \mathrm{m}$ slices using a Leica cryostat. Sections were directly mounted on pretreated slides (Superfrost Plus; Menzel Glaser, Braunschweig, Germany), air dried, and fixed in acetone/methanol (1:2) at room temperature for $10 \mathrm{~min}$. The slices were analyzed using Heidenhain's AZAN trichrome staining. The conventional dyes azocarmine $\mathrm{G}$ and aniline blue were used providing red nuclei as well as blue collagen-rich ECM and acid mucus substances. 
Monolayer cultures (2D): $\square 24 \mathrm{~h} \quad \square 48 \mathrm{~h} \quad \square 72 \mathrm{~h}$

A

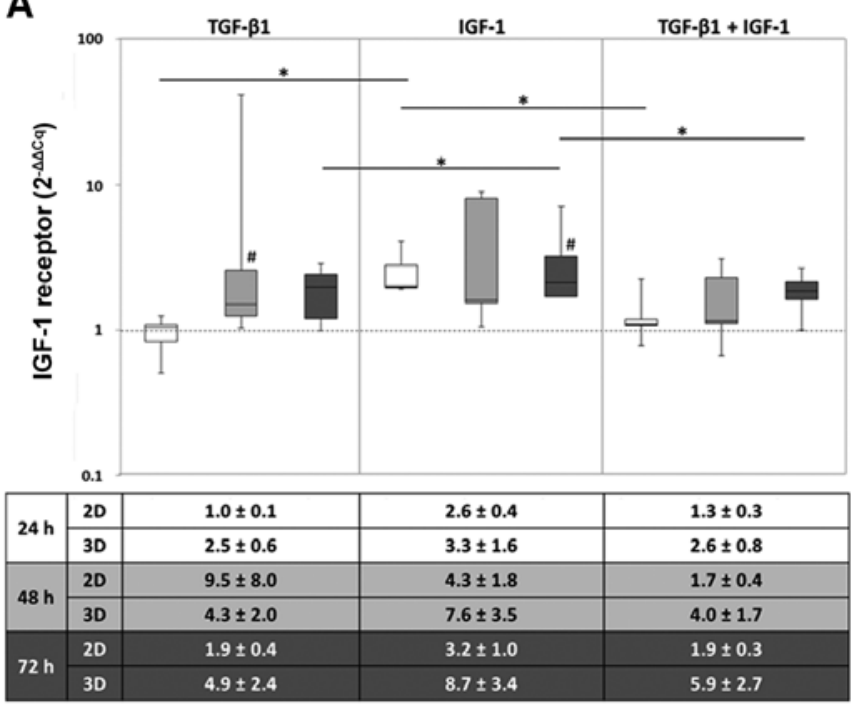

B

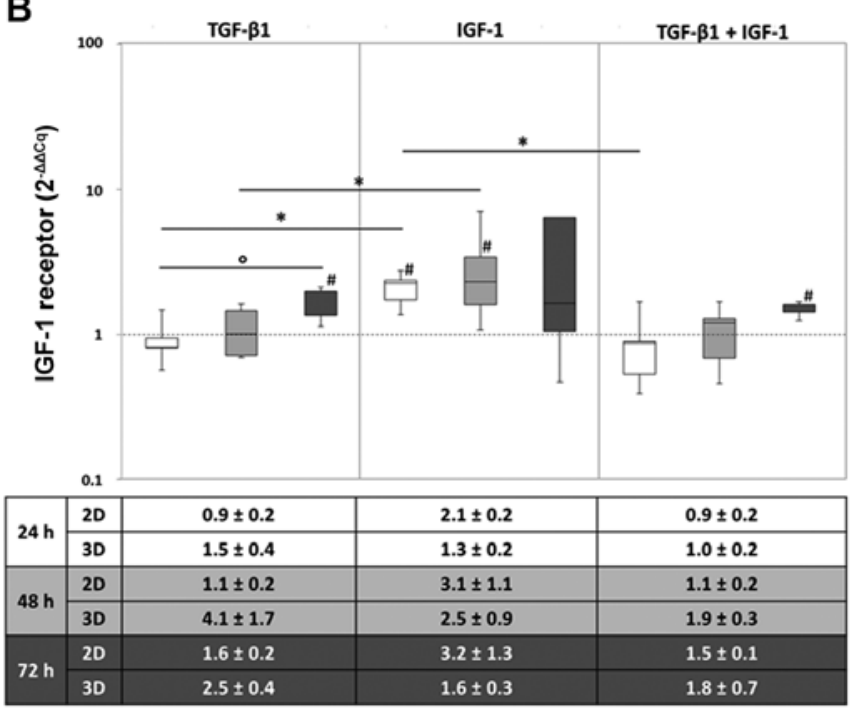

Figure 1. Expression of the IGF-1 receptor in (2D) monolayer and (3D) pellet cultures under (A) hypoxic and (B) normoxic culture conditions. Human chondrocytes were cultured as monolayer or pellet cultures and stimulated with TGF- $\beta 1$ and/or IGF-1. After 24,48 and 72 h, RNA was isolated and the gene expression rate of the IGF-1 receptor was quantified using qPCR. Data in the diagrams (from monolayer cultures) are presented as box plots with median, interquartile ranges and minimum/maximum values $(n=5)$. Statistical analysis was conducted using the Wilcoxon signed rank test. "P $\leq 0.05$, comparison between growth factors; ${ }^{\circ} \mathrm{P} \leq 0.05$, comparison between time points; ${ }^{~} \mathrm{P} \leq 0.05$, comparison to the starting time point $(0 \mathrm{~h})$. Data in the tables in the bottom panels are presented as the mean values \pm SEM from monolayer $(2 \mathrm{D}, \mathrm{n}=5)$ and pellet $(3 \mathrm{D}, \mathrm{n}=3)$ cultures. IGF-1, insulin-like growth factor-1; TGF- $\beta 1$ transforming growth factor- $\beta 1$.

Statistical analysis. Data in the diagrams are presented as box plots. Boxes denote interquartile ranges, horizontal lines within the boxes denote medians, and whiskers denote minimum and maximum values $(n=5)$. All statistical analyses were performed using SPSS statistics 22 (IBM Deutschland, Ehningen, Germany). Since all cultures of each specific donor were obtained from the same starting cultures, measurements could be estimated as repeated ones from a single sample. Therefore, the statistical significance was calculated with the Wilcoxon signed rank rest. $\mathrm{P}<0.05$ was considered to indicate a statistically significant difference.

\section{Results}

Gene expression rates of the IGF-1 receptor. In monolayer cultures, the IGFIR gene was mainly expressed when chondrocytes were stimulated with IGF-1 alone. Here, the mRNA levels after $72 \mathrm{~h}$ were significantly higher after IGF-1 stimulation compared to TGF- $\beta 1$ and/or IGF-1 stimulation under hypoxic culture conditions (all: $\mathrm{P}=0.043$ ) (Fig. 1A). Under normoxia, significant differences between the sole stimulation with TGF- $\beta 1$ and IGF- 1 were also detectable after 24 and $48 \mathrm{~h}$ (both: $\mathrm{P}=0.043)$ (Fig. 1B).

Additionally, an increased expression level of $I G F 1 R$ was observed over time, which was more marked for the stimulation with TGF- $\beta 1$ and the combination of TGF- $\beta 1$ and IGF-1. Indeed, this can be shown by a significant increase under normoxia and TGF- $\beta 1$ stimulation from 24 to $72 \mathrm{~h}(\mathrm{P}=0.043)$ (Fig. 1). Furthermore, comparable tendencies in gene expression levels between monolayer and pellet cultures regarding $I G F 1 R$ expression were detected. Nevertheless, the resulting differences were more decisive for cells cultured in monolayer.
This behaviour is exemplified by the mean values \pm SEM presented in the tables below the diagrams (Fig. 1).

Gene expression rates of the TGF- $\beta$ - receptors. The expression of the TGFBRl gene was enhanced after stimulation with TGF- $\beta 1$ alone or in combination with IGF-1. It was apparent that the highest TGFBR $1 \mathrm{mRNA}$ level was reached after $24 \mathrm{~h}$ with no marked changes over time. Hence, under hypoxic conditions, the expression levels were significantly enhanced in comparison to the starting point for TGF- $\beta 1$ and the combined stimulation (all: $\mathrm{P}=0.043$ ) (Fig. 2A). However, a significant difference between the different growth factors was observed under normoxia for TGF- $\beta 1$ and IGF-1 stimulation after $24 \mathrm{~h}(\mathrm{P}=0.043)$ (Fig. 2B). Moreover, comparing mRNA levels of monolayer and pellet cultures, similar patterns could be detected for the TGFBRI gene expression profile, although differences in the expression levels were more pronounced in the monolayer culture.

Regarding TGFBR2 gene expression, a notable increase in the mRNA levels was observed under IGF-1-stimulation. As in the same way observed for TGFBR1, TGFBR2 reached maximum expression levels already after $24 \mathrm{~h}$, which did not considerably change during further cultivation. Thus, compared to the starting point, significantly enhanced expression levels for all measured time points were determined under hypoxic conditions after IGF-1 stimulation (all: $\mathrm{P}=0.043$ ). Additionally, TGF- $\beta 1$ stimulation resulted in significantly enhanced expression levels after $72 \mathrm{~h}$ in comparison to the starting point $(\mathrm{P}=0.043)$ (Fig. 3A). Under normoxic culture onditions, TGFBR2 was significantly expressed at a higher level under IGF-1 stimulation compared to the sole stimulation with TGF- $\beta 1$ at all measured time points and compared to the combined stimulation TGF- $\beta 1$ and IGF-1 after 24 and $48 \mathrm{~h}$ (all: 
Monolayer cultures (2D): $\square 24 \mathrm{~h} \square 48 \mathrm{~h} \quad \square 72 \mathrm{~h}$

A

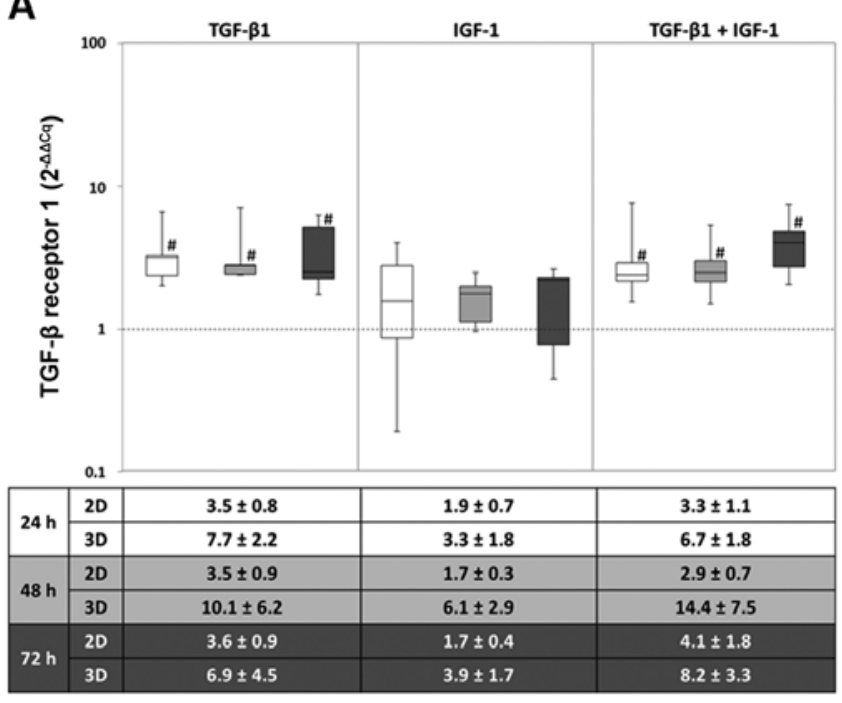

B

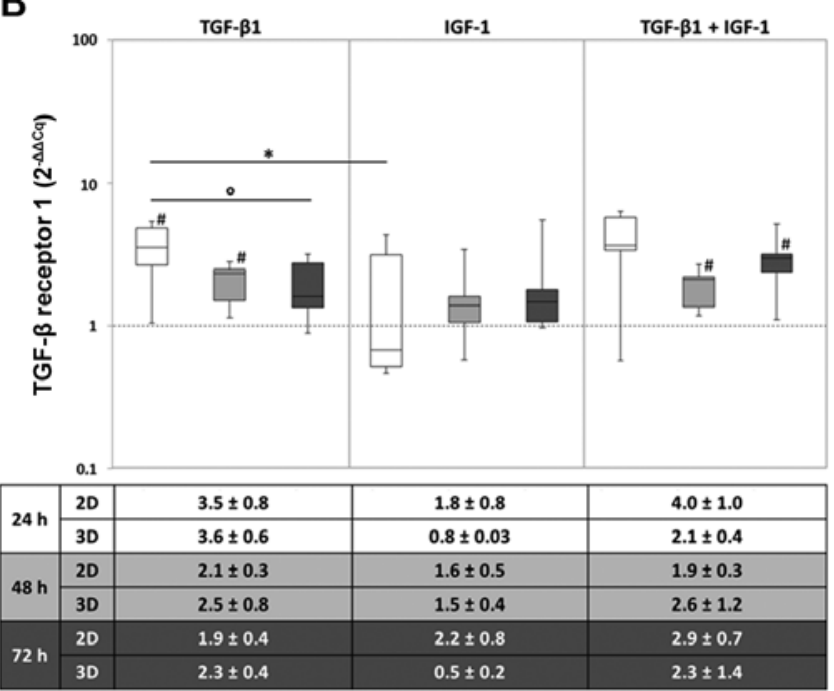

Figure 2. Expression of the TGF- $\beta$ receptor 1 in (2D) monolayer and p (3D) pellet cultures under (A) hypoxic and (B) normoxic culture conditions. Human chondrocytes were cultured as monolayer or pellet cultures and stimulated with TGF- $\beta 1$ and/or IGF-1. After 24,48 and $72 \mathrm{~h}$, RNA was isolated and the gene expression rate of the TGF- $\beta$ receptor 1 was quantified using qPCR. Data within the diagrams (from monolayer cultures) were presented as box plots with median, interquartile ranges and minimum/maximum values $(\mathrm{n}=5)$. Statistical analysis was done using the Wilcoxon Signed Rank Test. "P $\leq 0.05$, comparison between growth factors; ${ }^{\circ} \mathrm{P} \leq 0.05$, comparison between time points; ${ }^{\prime} \mathrm{P} \leq 0.05$, comparison to the starting time point $(0 \mathrm{~h})$. Data in the tables in the bottom panels are presented as the mean values \pm SEM from monolayer $(2 \mathrm{D}, \mathrm{n}=5)$ and pellet $(3 \mathrm{D}, \mathrm{n}=3)$ cultures. TGF- $\beta 1$ transforming growth factor- $\beta 1$; IGF-1, insulin-like growth factor-1.

Monolayer cultures (2D): $\square 24 \mathrm{~h} \square 48 \mathrm{~h} \quad \square 72 \mathrm{~h}$

A

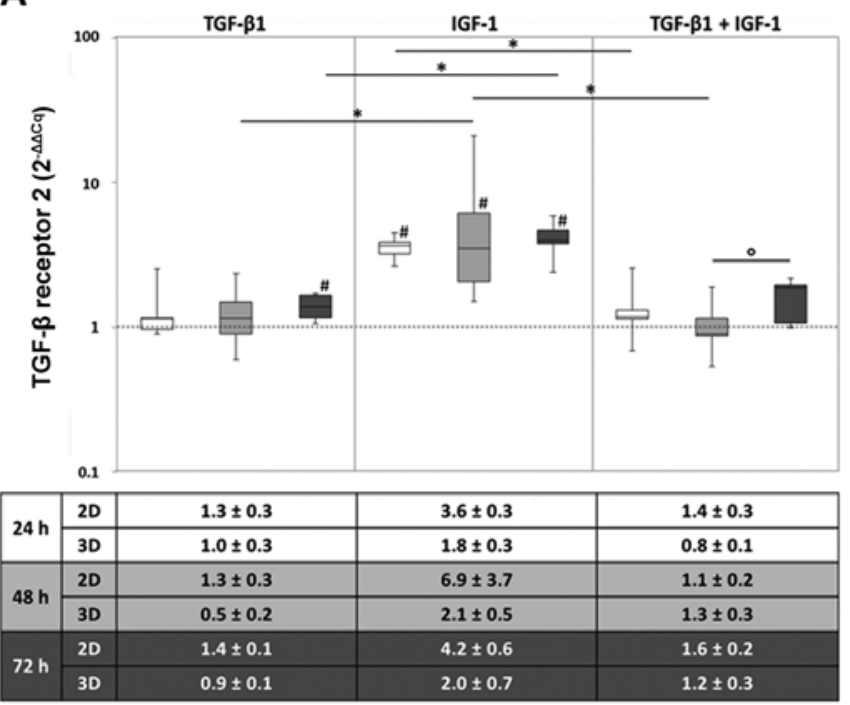

B

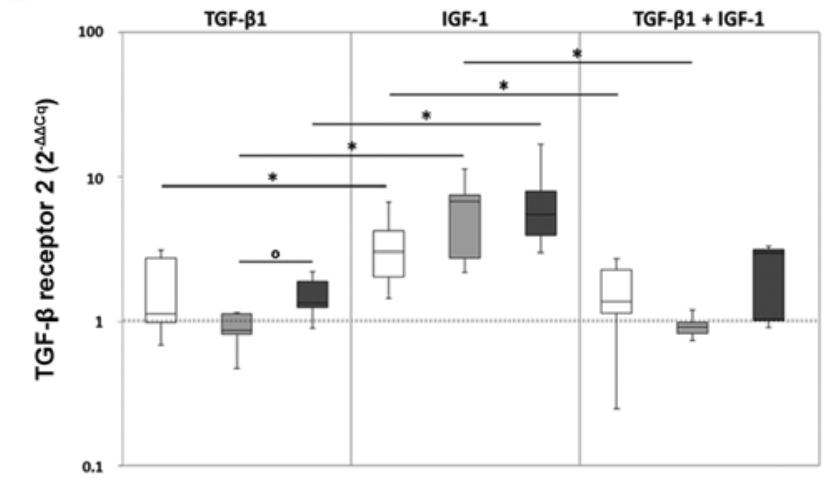

\begin{tabular}{|c|c|c|c|c|}
\hline \multirow{2}{*}{$24 \mathrm{~h}$} & $2 D$ & $1.7 \pm 0.5$ & $3.5 \pm 0.9$ & $1.6 \pm 0.4$ \\
\cline { 2 - 5 } & $3 D$ & $1.2 \pm 0.8$ & $2.2 \pm 1.3$ & $0.9 \pm 0.5$ \\
\hline \multirow{2}{*}{$48 \mathrm{~h}$} & $2 D$ & $0.9 \pm 0.1$ & $6.1 \pm 1.7$ & $1.0 \pm 0.1$ \\
\cline { 2 - 5 } & $3 D$ & $1.0 \pm 0.6$ & $3.7 \pm 1.9$ & $1.0 \pm 0.6$ \\
\hline \multirow{2}{*}{$72 \mathrm{~h}$} & $2 D$ & $1.5 \pm 0.2$ & $7.5 \pm 2.5$ & $2.2 \pm 0.5$ \\
\cline { 2 - 5 } & $3 D$ & $1.0 \pm 0.3$ & $2.5 \pm 1.2$ & $0.9 \pm 0.4$ \\
\hline
\end{tabular}

Figure 3. Expression of the TGF- $\beta$ receptor 2 in (2D) monolayer and (3D) pellet cultures under (A) hypoxic and (B) normoxic culture conditions. Human chondrocytes were cultured as monolayer or pellet cultures and stimulated with TGF- $\beta 1$ and/or IGF-1. After 24,48 and $72 \mathrm{~h}$, RNA was isolated and the gene expression rate of the TGF- $\beta$ receptor 2 was quantified using qPCR. Data in the diagrams (from monolayer cultures) are presented as box plots with median, interquartile ranges and minimum/maximum values $(\mathrm{n}=5)$. Statistical analysis was conducted using the Wilcoxon signed rank test. " $\mathrm{P} \leq 0.05$, comparison between growth factors; ${ }^{\circ} \mathrm{P} \leq 0.05$, comparison between time points; ${ }^{\#} \mathrm{P} \leq 0.05$, comparison to the starting time point $(0 \mathrm{~h})$. Data in the tables in the bottom panels are presented as the mean values \pm SEM from monolayer (2D, $n=5)$ and pellet $(3 \mathrm{D}, \mathrm{n}=3$ ) cultures. TGF- $\beta 1$ transforming growth factor- $\beta 1$; IGF- 1 , insulin-like growth factor-1.

$\mathrm{P}=0.043$ ) (Fig. 3B). Again, the gene expression levels between monolayer and pellet cultures revealed comparable tendencies.

Overall, no significant differences in receptor gene expression behaviour comparing monolayer and pellet culture was determined. Characteristic gene expression profiles of the growth factor receptors were determined in regards to the applied growth factors, although the values were partially widely scattered among the 5 donors. Moreover, it was apparent that $I G F 1 R$ showed an increase in mRNA levels over time whereas both $T G F B R s$ already reached maximum expression levels after $24 \mathrm{~h}$ and remained almost constant over time. 


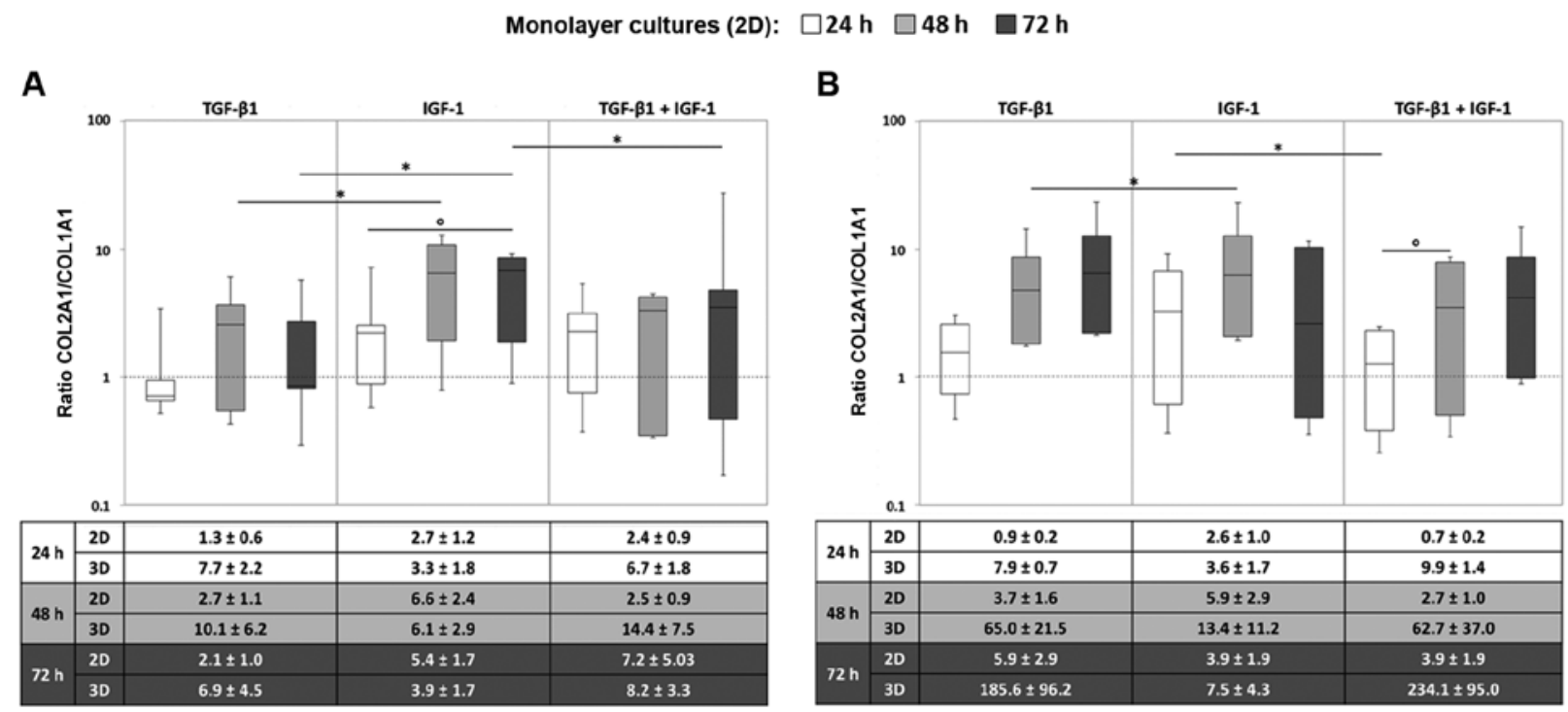

Figure 4. Ratio of collagen type 2 and type 1 in monolayer (2D) and (3D) pellet cultures under (A) hypoxic and (B) normoxic culture conditions. Human chondrocytes were cultured as monolayer or pellet cultures and stimulated with TGF- $\beta 1$ and/or IGF-1. After 24,48 and $72 \mathrm{~h}$, RNA was isolated and the gene expression rate of collagen type 2 and type 1 were quantified using qPCR. Data in the diagrams (from monolayer cultures) are presented as box plots with median, interquartile ranges and minimum/maximum values $(\mathrm{n}=5)$. Statistical analysis was conducted using the Wilcoxon signed rank test. "P $\leq 0.05$, comparison between growth factors; ${ }^{\circ} \mathrm{P} \leq 0.05$, comparison between time points; ${ }^{*} \mathrm{P} \leq 0.05$, comparison to the starting time point $(0 \mathrm{~h})$. Data in the tables in the bottom panels are presented as the mean values \pm SEM from monolayer $(2 \mathrm{D}, \mathrm{n}=5)$ and pellet $(3 \mathrm{D}, \mathrm{n}=3)$ cultures. TGF- $\beta 1$ transforming growth factor- $\beta 1$; IGF-1, insulin-like growth factor-1.

Gene expression of COL1A1 and COL2A1. In order to analyze the relation between $C O L 1 A 1$ and $C O L 2 A 1$, and therefore the quality of cartilogenous pellet cultures, COL $2 A 1 / C O L 1 A 1$ ratios were determined.

In most cases, we observed an increase in the ratio over time. In general, the ratios for the monolayer cultures reached higher values under stimulation with IGF-1 in comparison to the stimulation with TGF- $\beta 1$ or the combination of TGF- $\beta 1$ and IGF-1. This was observed for both oxygen conditions. Most of the donors showed a time-dependent increase in the ratios, especially when they were stimulated with TGF- $\beta 1$ or the combination. In contrast to that, the ratios under IGF-1 stimulation altogether fluctuated at higher values, but rarely increased in a steady manner as was the case for TGF- $\beta 1$ and the combination (Fig. 4).

Upon comparing the monolayer and pellet cultures, the COL2A1/COL1A1 ratios reached higher values for the pellet cultures especially when they were stimulated with TGF- $\beta 1$ or with both growth factors. Similar to the monolayer culture under hypoxic conditions, a time-dependent increase in the ratios in chondrocytic pellets was detected after treatment with TGF- $\beta 1$ or the combination (Fig. 4A). This increase over time was even more marked for the pellet cultures. Nonetheless, regarding the COL $2 A 1 / C O L 1 A 1$ ratios, no significant differences for the ratios between the two culturing methods were found.

In addition, a prominent increase in the ratios in the pellet cultures after 14 and 35 days after stimulation with TGF- $\beta 1$ and the combination was detected. After 35 days we observed higher ratios for the combination of IGF- 1 and TGF- $\beta 1$ compared to the sole stimulation. This was detectable for both oxygen conditions but was more pronounced under hypoxia. Nevertheless, the ratios were widely scattered among the three donors, which is indicated by the high standard errors of the mean (SEM) (Fig. 4).

Gene expression of hypertrophic markers. In order to detect hypertrophy of cells, the gene expression of ALP and COL10A1 was analyzed from pellet cultures after 24,48 and $72 \mathrm{~h}$ as well as after 14 and 35 days.

Gene expression of $A L P$ was not induced in the chondrocytic pellet cultures. In most of the cases the gene expression level was lower than that of the unstimulated cells at time point 0 or did not extend detectable ranges. The highest detected value was a 1.7-fold increase compared to the unstimulated control obtained for TGF- $\beta 1$ stimulation after $48 \mathrm{~h}$ of cultivation under hypoxia (for donor 2), but the expression level decreased over time to a 0.07 -fold value ( 35 days, TGF- $\beta 1$ stimulation). Furthermore, the expression levels did not differ between the different stimulation types or between the two oxygen conditions. COL10Al gene expression was not detectable in most of the samples. There were no detectable expression levels at time point 0 , hence $2^{-\Delta \Delta \mathrm{Cq}}$ values could not be calculated. Instead, expression levels were related to the expression of the housekeeper gene $\beta$-actin. Some low expression rates were detected in cultures treated with TGF- $\beta 1$ or the combination of TGF- $\beta 1$ and IGF-1. Nevertheless, the detected rates did not exceed $0.1 \%$ of the expression level of the housekeeper.

Synthesis rates of hyaline cartilage-like ECM components. In addition to gene expression analyses, levels of the hyaline-characteristic proteins $\mathrm{Col} 2$ as well as sGAG were quantified from supernatants of the chondrocytic pellet cultures to determine the redifferentiation potential.

Overall the measured $\mathrm{Col} 2$ amounts were higher under hypoxia (Fig. 5A) than under normoxia (Fig. 5B). Comparing 
A

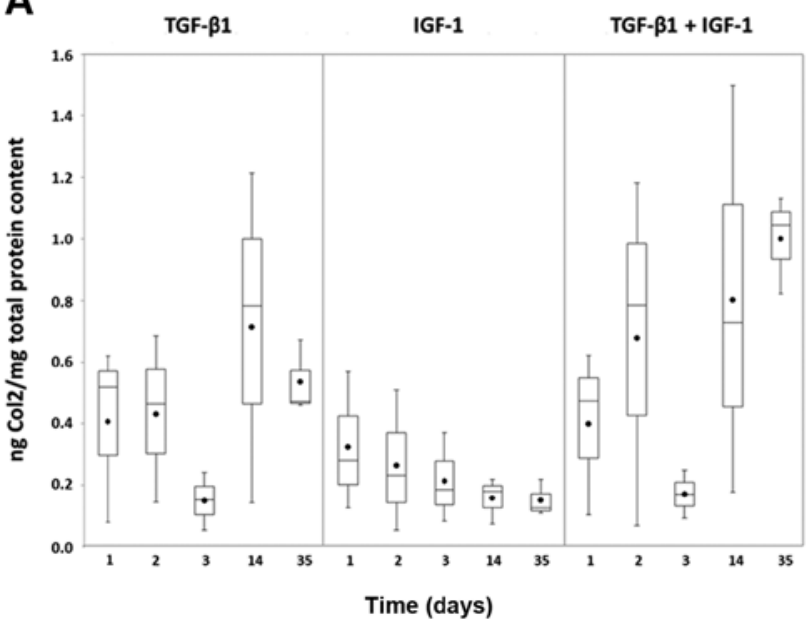

B

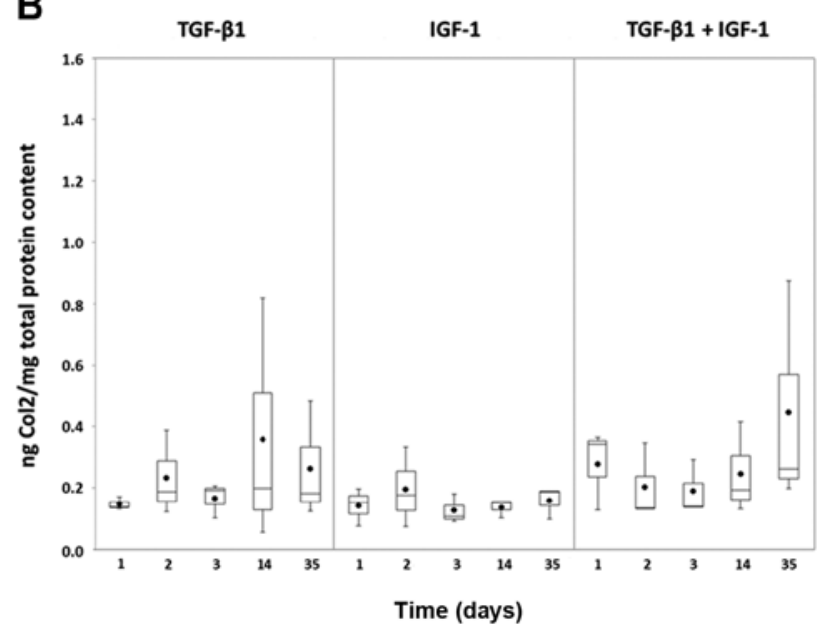

Figure 5. Synthesis rate of collagen type 2 in chondrocytic pellet cultures under (A) hypoxic and (B) normoxic culture conditions. Human chondrocytes were cultured as pellet cultures and stimulated with TGF- $\beta 1$ and/or IGF-1. After 24, 48, $72 \mathrm{~h}$ as well as 14 and 35 days, supernatants of each stimulating experiment were analysed by ELISA. Protein content was calculated using a defined standard curve and afterwards related to the total protein content (ng/mg). Data in the diagrams are presented as box plots with median, interquartile ranges and minimum/maximum values ( $\mathrm{n}=3$ ). Additionally, dots within boxes indicate the mean values. No statistical significance was detected (Wilcoxon Test). TGF- $\beta 1$ transforming growth factor- $\beta 1$; IGF-1, insulin-like growth factor-1.

A

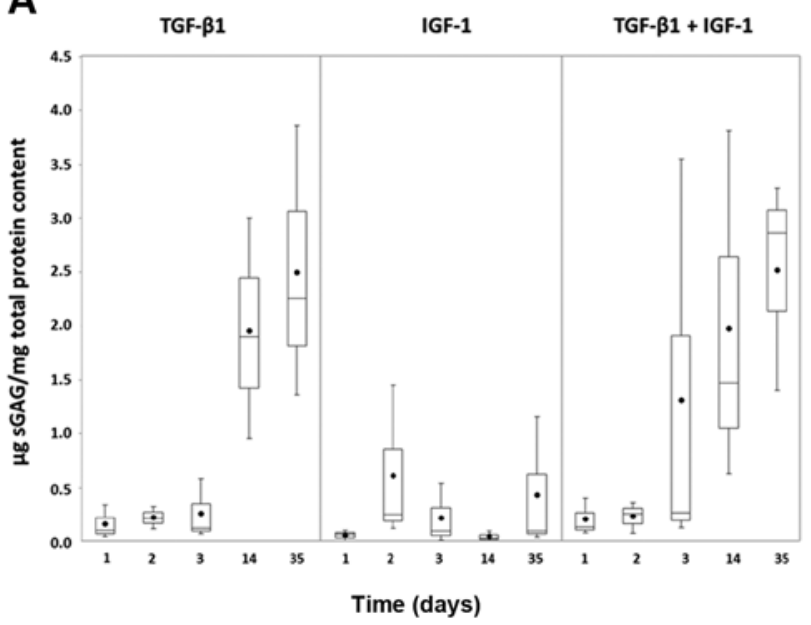

B

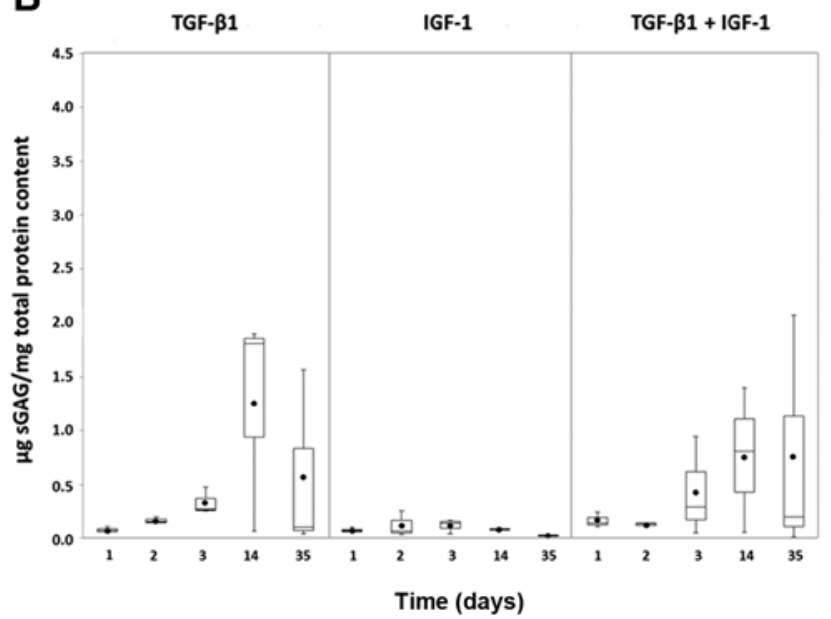

Figure 6. Synthesis rate of sGAG in chondrocytic pellet cultures under (A) hypoxic and (B) normoxic culture conditions. Human chondrocytes were cultured as pellet cultures and stimulated with TGF- $\beta 1$ and/or IGF-1. After 24, 48, $72 \mathrm{~h}$ as well as 14 and 35 days, supernatants of each stimulating experiment were digested overnight with papain $\left(65^{\circ} \mathrm{C}\right)$ and afterwards analysed by Blyscan. The sGAG content was calculated using a defined standard curve and related to the total protein content $(\mu \mathrm{g} / \mathrm{mg})$. Data in the diagrams are presented as box plots with median, interquartile ranges and minimum/maximum values ( $\mathrm{n}=3$ ). Additionally, dots within boxes indicate the mean values. No statistical significance was detected (Wilcoxon Test). sGAG, sulphated glycosaminoglycan; TGF- $\beta 1$ transforming growth factor- $\beta 1$; IGF-1, insulin-like growth factor-1.

the different stimulations, greatest protein amounts were reached with TGF- $\beta 1$ and the combination of TGF- $\beta 1$ and IGF-1. Nevertheless, a conspicuous decrease was observable for these two stimulations under hypoxia at day 3 with increasing values at the later measured points (14 and 35 days) (Fig. 5A).

Only less Col 2 protein could be detected from the pellet cultures stimulated with IGF-1. Under hypoxia the amount decreased over time (Fig. 5A), whereas under normoxia it remained at a low level (Fig. 5B).

Similar to Col2 protein amounts, the sGAG reached higher levels under hypoxia (Fig. 6A) than under normoxia (Fig. 6B). The amount of sGAG produced by the pellet cultures stimulated with TGF- $\beta 1$ alone or in combination with TGF- $\beta 1$ and IGF-1 increased over time. This tendency was more visible under hypoxia (Fig. 6A). In contrast, under both oxygen conditions, only low amounts of sGAG were detected under IGF-1 stimulation which remained almost stable over time.

Morphological and histological characterization of pellet cultures. During incubation of the chondrocyte pellet cultures over 35 days under different growth factor combinations and oxygen conditions the cell pellets developed unequal sizes. After 35 days of incubation, the pellets stimulated with TGF- $\beta 1$ or the combination of TGF- $\beta 1$ and IGF- 1 were approximately twice as large as pellets stimulated with IGF-1 alone. For pellets cultured under normoxia, we could even observe a reduction in pellet size over time. This difference in size after 35 days of culturing is indicated in Fig. 7. Additionally, an enhanced 


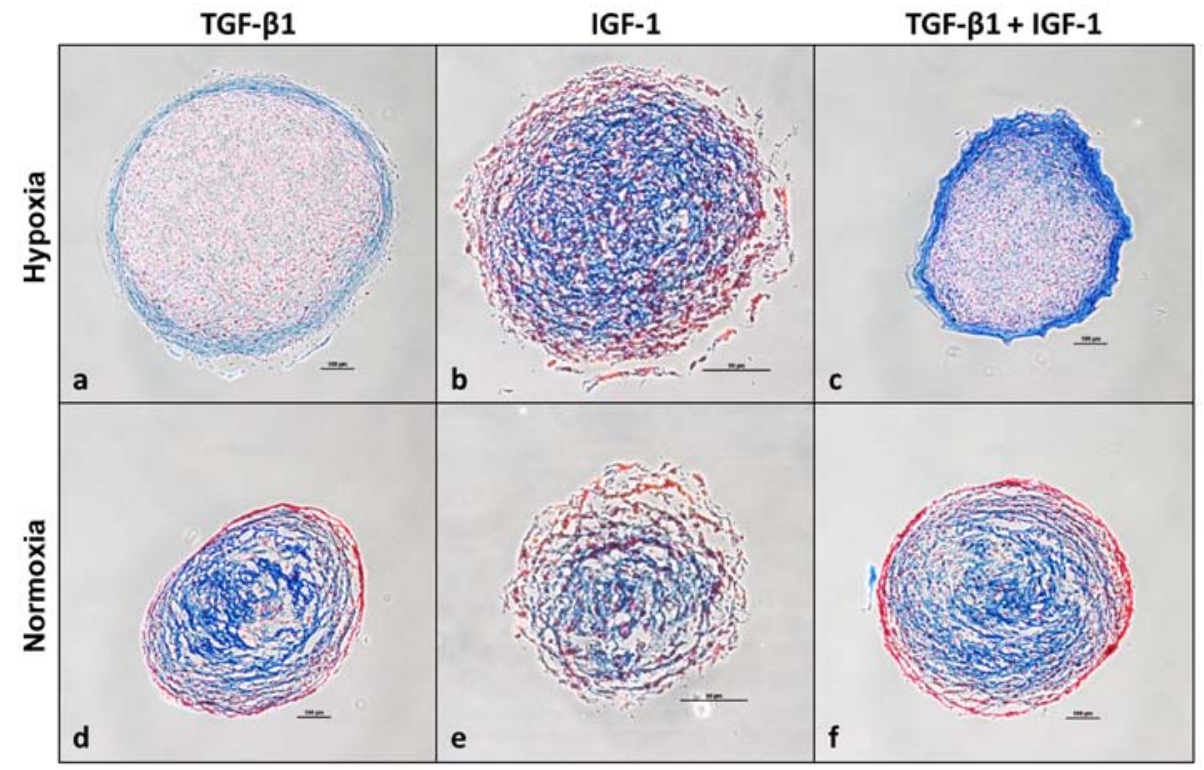

Figure 7. AZAN staining of chondrocytic pellet cultures under (a-c) hypoxic and (d-f) normoxic culture conditions. Human chondrocytes were cultured as pellet cultures and stimulated with TGF- $\beta 1$ and/or IGF-1. After 35 days of incubation, pellet cultures were cryo-conserved in Tissue Tek at $-80^{\circ} \mathrm{C}$ and afterwards sectioned to 7 - to $10-\mu \mathrm{m}$ slices using a Leica cryostat. Pellets were analysed using Heidenhain's AZAN trichrome staining indicating collagen-rich extracellular matrix in blue and nuclei as well as cytoplasm in red. Scale bar, $50 \mu \mathrm{m}$ (IGF-1); $100 \mu \mathrm{m}$ (TGF- $\beta 1$; TGF- $\beta 1+$ IGF-1). IGF-1, insulin-like growth factor-1; TGF- $\beta 1$ transforming growth factor- $\beta 1$.

robustness of the pellet cultures against homogenisation was observed over increasing culturing time. This enhancement in robustness was more pronounced for pellets cultured under hypoxia combined with TGF- $\beta$ or TGF- $\beta$ and IGF-1 stimulation.

Additionally, pellet cultures were histologically analyzed after 35 days of incubation using Heidenhain's AZAN trichrome staining indicating collagen-rich ECM in blue and nuclei as well as cytoplasm in red. Pellets stimulated under hypoxia (Fig. 7a-c) appeared more compact and homogenous compared to those stimulated under normoxia (Fig. 7d-f). Blue stained marginal sides of pellets stimulated with TGF- $\beta 1$ or the combination of TGF- $\beta 1$ and IGF- 1 under hypoxia indicate the localization of collagen-rich ECM as well as acid mucus substances (Fig. 7a and c). Referring to Fig. 7c, representing a section of a pellet which was cultured under hypoxia and stimulated with the combination of TGF- $\beta 1$ and IGF- 1 , it is prominent that among all stained sections its periphery is mostly deep-blue stained. This is in contrast to IGF-1 stimulated pellet cultures from hypoxia (Fig. 7b) and to the pellet cultures cultured under normoxia (Fig. 7a-f). Here blue collagen-rich ECM and acid mucus substances are rather located in the centre of the section than in the periphery.

\section{Discussion}

Previous in vitro studies have already examined growth factor receptor expression on TGF- $\beta 1$ - and/or IGF-1-stimulated bovine $(25,26)$ or leporine chondrocytes $(27)$. To our knowledge, no studies have been carried out to date dealing with donor-specific growth factor responsiveness of human chondrocytes. Accordingly, our study presents a new approach to investigate whether the targeted use of growth factors deduced from specific receptor gene expression profiles on the surface of human chondrocytes can positively influence the redifferentiation potential of dedifferentiated chondrocytic cells.
Gene expression of IGF-1 and TGF- $\beta$ receptors. In monolayer cultures, significant differences in receptor mRNA levels in dependency to the applied growth factor were determined.

These results indicate an upregulation of $I G F I R$ and $T G F B R 1$ gene expression by the corresponding growth factors IGF-1 and TGF- $\beta 1$, respectively. Several in vitro studies have previously demonstrated the capacity of TGF- $\beta 1$ to regulate the expression of its own receptors in rabbit periosteal explants (27), human hepatoma cell lines (28) or human small cell lung cancer cell lines (29), respectively. Moreover, a positive autoregulatory action was also demonstrated for IGF-1 on IGFIR by Davies et al (26) in bovine chondrocytes and in granulosa cells by deMoura et al (30). In contrast, TGFBR2 gene expression was not upregulated by its corresponding growth factor TGF- $\beta 1$. As described by Barbara et al (31), TGF- $\beta 1$ acts through an heterologous complex composed of $T G F B R 1$ and $T G F B R 2$, suggesting that both complex partners should be present in an adequate amount to upregulate the total receptor complex. Nevertheless, we could not demonstrate that the heterologous TGF- $\beta$-receptor complex partners were simultaneously expressed at the mRNA level. The gene expression of both receptors changed rather in dependency on growth factor stimulation. It could be assumed that TGFBR2 was already expressed at a higher level at the starting point, thus further upregulation was not required. TGF- $\beta 1$ may compensate the deficiency of the limiting receptor subunit $T G F B R 1$ by its upregulation in order to improve sensitivity of chondrocytes towards TGF- $\beta 1$ stimulation. The higher expression of TGFBR2 under IGF-1 stimulation could also be explained by gene regulation mechanisms. Possible, due to a deficit of the corresponding ligand (here, TGF- $\beta 1$ ), the receptor is upregulated in chondrocytes in order to increase sensitivity.

Moreover, it was apparent that the $I G F 1 R$ rather showed an increase in mRNA level over time whereas both TGFBRs already reached maximum expression levels after $24 \mathrm{~h}$ and 
remained almost constant over time. A possible explanation for this behaviour could be a faster degradation time of TGFBRs mRNA compared to IGFIR mRNA indicating mRNA accumulation over time. As a consequence, the amount of transcribed and degraded mRNA is in balance, leaving the TGFBRs mRNA level unchanged. In the present study, we only analyzed growth factor receptor expression at the mRNA level. In further studies, we must examine how the receptor mRNA levels correlate with corresponding protein levels.

However, our findings denote that the chondrogenic growth factors could influence the gene expression profile of $I G F 1 R$, $T G F B R 1$ and TGFBR2. Moreover, the values were partially widely scattered among the donors indicating the existence of donor-specific responsiveness towards growth factor stimulation.

Comparing the two different oxygen concentrations (21 vs. 5\%), we observed more pronounced gene expression profiles under hypoxia implying better response ability under physiological conditions. Furthermore, no significant differences in receptor gene expression behaviour comparing monolayer and pellet culture were determined. Therefore, pellet culturing for analysis of receptor gene expression patterns seems to have no benefit, suggesting monolayer culturing suitable for the establishment of an analysis tool to deduce growth factor responsiveness.

Differentiation capacity of chondrocytic cells. Although the ratios for the monolayer cultures reached higher values under stimulation with IGF-1 compared to the stimulation with TGF- $\beta 1$ or the combination of TGF- $\beta 1$ and IGF- 1 , most of the cultures showed an increase in the ratios over time under the latter stimulations. Assuming further increases in the ratios under stimulation with TGF- $\beta 1$ or the combination for prolonged cultivation, it might be possible that the ratios even exceed the ones under stimulation with IGF-1. This assumption could be supported by the prominent increase in ratios in pellet cultures after 14 and 35 days after stimulation with TGF- $\beta 1$ and the combination but not for IGF-1 alone, suggesting a greater impact of TGF- $\beta 1$ on the hyaline cartilage characteristic COL2A1 gene expression.

Furthermore, after 35 days, higher COL2A1/COL1A1 ratios were detected for the combination of IGF- 1 and TGF- $\beta 1$ compared to the sole stimulation. This was observed for both oxygen conditions, but was more pronounced under hypoxia. This finding suggests an additive effect of both growth factors, which was also observed in previous studies (23) as well as by other research groups $(18,32,33)$. Additionally, it was previously reported that intracellular signalling pathways of TGF- $\beta 1$ and IGF-1 are partially linked (7,34). The connection of both pathways could be a hint for an additive effect of both growth factors on the chondrogenic differentiation. Nonetheless the signalling pathways are not fully understood to date (7).

The detection of higher COL2A1/COL1Al ratios in the pellet cultures in comparison to those noted in the monolayer cultures suggests the dependency of three-dimensional culturing as a chondrogenic stimulus itself. It is already known that phenotypes and gene expression of chondrocytes are highly dependent on the enclosing ECM and cell-to-cell contact (35). The close three-dimensional contact of chondrocytes enables efficient autocrine stimulation and enhances sythesis of ECM components (36). Our results support the previously described findings. Nevertheless, varying $C O L 2 A 1 / C O L 1 A 1$ ratios among the donors, dependent on the applied growth factors presumably denote donor-specific redifferentiation potentials.

Comparing Col2 and sGAG synthesis rates of pellet cultures, enhanced amounts of ECM components were detected under hypoxia and stimulation with TGF- $\beta 1$ or with the combination with IGF-1, whereas they were low for the sole stimulation with IGF-1. This finding also suggests an anabolic effect of TGF- $\beta 1$ on the synthesis of Col 2 and sGAG and again a promotive effect of physiological oxygen content. The results for the $\mathrm{Col} 2$ protein expression were consistent with the mRNA expression levels of COL2Al after 14 and 35 days, confirming the correlation of gene and protein expression. However, no additive effect of both growth factors could be found on the protein level similar to the case for the mRNA level. A delay in the translation from mRNA to the protein could be a possible explanation for the absent additive effect on the protein level.

The increased protein amounts of Col 2 and sGAG in pellet cultures after incubation with TGF- $\beta 1$ or the combination of TGF- $\beta 1$ and IGF-1 were in relation to enhanced TGFBRI expression of the different donors, supposing the possibility to derive the responsiveness to TGF- $\beta 1$ and/or IGF- 1 from the increase in mRNA levels of the corresponding receptors.

Altogether, the detection of higher COL2A1/COL1A1-ratios as well as higher Col2 and sGAG amounts after TGF- $\beta 1$ stimulation alone or in combination with IGF-1 under hypoxia confirm the positive impact of physiologically approximated culture conditions on the redifferentiation potential. Moreover, gene expression of $A L P$ and COL1OAl was not induced in pellet cultures, giving no evidence for the emergence of hypertrophic processes and the development of fibrocartilage.

Furthermore, we examined COL2A1/COL $1 A 1$-ratios in unstimulated cultures, using only ITS-supplement in the cell culture media. These control cultures showed almost similar results as the cultures treated with IGF-1. We suppose that these effects may be explained by the supplemented insulin in the ITS-reagent. Because of molecular similarities between insulin and IGF-1, both interact on same receptor binding sites (37). Therefore, insulin probably simulated the effects of IGF-1 by the upregulation of same pathways.

Morphological and histological characterization of pellet cultures. The variation of pellet size and metabolic activity in relation to different growth factor stimulation and different oxygen conditions confirm the dependency of pellet morphology on defined culturing conditions. An enhancement in pellet size under stimulation with TGF- $\beta 1$ or the combination of TGF- $\beta 1$ and IGF-1 suggests an enhancing effect of the applied growth factors either on proliferation or ECM production of human chondrocytes. The same can be estimated for the culturing under hypoxia due to an increase in pellet size. The reduction in pellet size under normoxia could probably be explained by an intensification of oxidative stress, driving cells towards apoptosis $(38,39)$. Bohensky et al $(40)$ previously showed that a reduced oxygen concentration prevents apoptosis of chondrocytes due to the expression of reactive oxygen species protective hypoxic-inducible transcription factors. Babur et al (41) compared human chondrocytic macropellets and micropellets under different oxygen conditions and 
likewise observed larger volumes as well as greater metabolic activity, sGAG production and higher $\mathrm{Col} 2$ expression of pellets cultivated under hypoxia, indicating a redifferentiation process.

Observed enhanced robustness under hypoxia combined with TGF- $\beta$ or TGF- $\beta$ and IGF- 1 stimulation may indicate that pellets gained robustness due to the production of hyaline-like ECM. This assumption would resemble the detected anabolic effect of TGF- $\beta 1$ on the Col 2 and sGAG expression.

Analysis of histological sections of the pellet cultures after 35 days indicated that pellets cultured under hypoxia appeared more compact. This finding was consistent with the morphological observations and enhanced levels of hyaline-like ECM components Col2 and sGAG. For pellets stimulated with TGF- $\beta 1$ or the combination of TGF- $\beta 1$ and IGF-1 under hypoxia, collagen-rich ECM as well as acid mucus substances were rather present at the marginal sides indicating a capsule-like formation of ECM. This capsule formation could also explain the higher resistance of these pellets to homogenization. Although the staining did not distinguish between fibrous-cartilaginous typical Coll and hyaline characteristic $\mathrm{Col} 2$, the enhancement in robustness may give a hint for the production of more mechanically resistant Col2.

In contrast, in IGF-1-stimulated pellets under hypoxia and in all pellet cultures under normoxia, the ECM was rather located in the centre of the histological sections.

One could speculate that the capsule-like formation could lead to a higher concentration of autocrine secreted growth factors (and other substances) within the pellet itself due to a reduced diffusion out of the capsule. This enhanced autocrine stimulation could promote the redifferentiation of the chondrocytes within the pellet construct. Therefore, the capsule-like formation might be more favourable than the central location of ECM in the pellets. On the other hand, less diffusion of nutrients into the centre of the pellets may impair cell viability. Thus, it remains unclear which ECM formation of the pellets is more beneficial to generate functional in vivo-like cartilage. This should be clarified in further studies.

In conclusion, we found characteristic gene expression profiles of $T G F B R s$ and $I G F 1 R$ according to the applied growth factors. These gene expression profiles were even more pronounced under hypoxia. Our findings support the assumption that the chondrogenic growth factors influence the gene expression of their corresponding receptors IGF1R, TGFBRI and $T G F B R 2$. Moreover, increased amounts of $\mathrm{Col} 2$ protein and sGAG after incubation with TGF- $\beta 1$ and/or IGF-1 were validated in pellet cultures. Further histological investigations also indicated that reduced oxygen conditions combined with the use of chondrogenic growth factors supported the generation of hyaline-like tissue. Nevertheless, further experiments with higher sample sizes and prolonged culturing time must be conducted to prove the applicability of a screening method on growth factor receptors. Moreover, the further examination of intracellular signalling pathways that are related to the redifferentiation process of human chondrocytes can be helpful to analyze possible interactions of growth factors at the molecular level. In further research, it is recommended to investigate protein levels of specific growth factor receptors either by flow cytometry or western blot analysis in order to examine the correlation of mRNA and protein levels. It may also be enlightening to sort TGF- $\beta 1$ and/or IGF-1 receptorpositive cells and determine their ability for redifferentiation.

Nonetheless, constructing a gene expression profile regarding mRNA levels of specific growth factor receptors in monolayer cultures is a valuable tool to predict the individual response of donors in growth factor application in vitro. The results of the present study could be a basis for further research on donor-specific cartilage regeneration to make the therapeutic attempt of chondrogenic redifferentiation more efficient in ex vivo cell expansion procedures.

\section{Acknowledgements}

The authors would like to thank Mrs. Frauke Winzer, Institute for Anatomy, University Medical Centre Rostock (Rostock, Germany) for supporting the sample preparation for the histological staining.

\section{References}

1. Loeser RF Jr: Aging cartilage and osteoarthritis - What's the link? Sci Aging Knowl Env 2004: pe31, 2004. doi: 10.1126/sageke.2004.29.pe31

2. Chiang $\mathrm{H}$ and Jiang C-C: Repair of articular cartilage defects: Review and perspectives. J Formos Med Assoc 108: 87-101, 2009.

3. Shi Y, Ma J, Zhang X, Li H, Jiang L and Qin J: Hypoxia combined with spheroid culture improves cartilage specific function in chondrocytes. Integr Biol 7: 289-297, 2015.

4. Tekari A, Luginbuehl R, Hofstetter W and Egli RJ: Transforming growth factor beta signaling is essential for the autonomous formation of cartilage-like tissue by expanded chondrocytes. PLoS One 10: e0120857, 2015.

5. Arzi B, DuRaine GD, Lee CA, Huey DJ, Borjesson DL, Murphy BG, Hu JC, Baumgarth N and Athanasiou KA: Cartilage immunoprivilege depends on donor source and lesion location. Acta Biomater 23: 72-81, 2015.

6. Schulze-Tanzil G: Activation and dedifferentiation of chondrocytes: Implications in cartilage injury and repair. Ann Anat 91: 325-338, 2009.

7. Duan L, Ma B, Liang Y, Chen J, Zhu W, Li M and Wang D: Cytokine networking of chondrocyte dedifferentiation in vitro and its implications for cell-based cartilage therapy. Am J Transl Res 7: 194-208, 2015.

8. Bhardwaj N, Devi D and Mandal BB: Tissue-engineered cartilage: The crossroads of biomaterials, cells and stimulating factors. Macromol Biosci 15: 153-182, 2015.

9. Fickert S, Gerwien P, Helmert B, Schattenberg T, Weckbach S, Kaszkin-Bettag $M$ and Lehmann L: One-year clinical and radiological results of a prospective, investigator-initiated trial examining a novel, purely autologous 3-dimensional autologous chondrocyte transplantation product in the knee. Cartilage 3: 27-42, 2012.

10. van der Kraan PM, Buma P, van Kuppevelt T and van den Berg WB: Interaction of chondrocytes, extracellular matrix and growth factors: Relevance for articular cartilage tissue engineering. Osteoarthritis Cartilage 10: 631-637, 2002.

11. van Osch GJ, van den Berg WB, Hunziker EB and Häuselmann HJ: Differential effects of IGF-1 and TGF beta- 2 on the assembly of proteoglycans in pericellular and territorial matrix by cultured bovine articular chondrocytes. Osteoarthritis Cartilage 6: 187-195, 1998.

12. Giovannini S, Diaz-Romero J, Aigner T, Mainil-Varlet P and Nesic D: Population doublings and percentage of S100-positive cells as predictors of in vitro chondrogenicity of expanded human articular chondrocytes. J Cell Physiol 222: 411-420, 2010.

13. Chubinskaya S, Hakimiyan A, Pacione C, Yanke A, Rappoport L Aigner T, Rueger DC and Loeser RF: Synergistic effect of IGF-1 and OP-1 on matrix formation by normal and OA chondrocytes cultured in alginate beads. Osteoarthritis Cartilage 15: 421-430, 2007.

14. McQuillan DJ, Handley CJ, Campbell MA, Bolis S, Milway VE and Herington AC: Stimulation of proteoglycan biosynthesis by serum and insulin-like growth factor-I in cultured bovine articular cartilage. Biochem J 240: 423-430, 1986. 
15. Guerne PA, Sublet A and Lotz M: Growth factor responsiveness of human articular chondrocytes: Distinct profiles in primary chondrocytes, subcultured chondrocytes, and fibroblasts. J Cell Physiol 158: 476-484, 1994.

16. Jones JI and Clemmons DR: Insulin-like growth factors and their binding proteins: Biological actions. Endocr Rev 16: 3-34, 1995.

17. Giannoni P and Cancedda R: Articular chondrocyte culturing for cell-based cartilage repair: Needs and perspectives. Cells Tissues Organs 184: 1-15, 2006.

18. Fukumoto T, Sperling JW, Sanyal A, Fitzsimmons JS Reinholz GG, Conover CA and O'Driscoll SW: Combined effects of insulin-like growth factor-1 and transforming growth factor-betal on periosteal mesenchymal cells during chondrogenesis in vitro. Osteoarthritis Cartilage 11: 55-64, 2003.

19. Redini F, Galera P, Mauviel A, Loyau G and Pujol JP Transforming growth factor beta stimulates collagen and glycosaminoglycan biosynthesis in cultured rabbit articular chondrocytes. FEBS Lett 234: 172-176, 1988.

20. Shi Y and Massagué J: Mechanisms of TGF-beta signaling from cell membrane to the nucleus. Cell 113: 685-700, 2003.

21. Bassing CH, Howe DJ, Segarini PR, Donahoe PK and Wang XF: A single heteromeric receptor complex is sufficient to mediate biological effects of transforming growth factor-beta ligands. J Biol Chem 269: 14861-14864, 1994.

22. Jonitz A,LochnerK,Peters K, Salamon A,Pasold J,Mueller-HilkeB, Hansmann D and Bader R: Differentiation capacity of human chondrocytes embedded in alginate matrix. Connect Tissue Res 52: 503-511, 2011.

23. Jonitz A, Lochner K, Tischer T, Hansmann D and Bader R TGF- $\beta 1$ and IGF- 1 influence the redifferentiation capacity of human chondrocytes in 3D pellet cultures in relation to different oxygen concentrations. Int J Mol Med 30: 666-672, 2012.

24. Pasold J, Zander K, Heskamp B, Grüttner C, Lüthen F, Tischer T, Jonitz-Heincke A and Bader R: Positive impact of IGF-1-coupled nanoparticles on the differentiation potential of human chondrocytes cultured on collagen scaffolds. Int J Nanomedicine 10: 1131-1143, 2015.

25. Yang Y-H and Barabino GA: Differential morphology and homogeneity of tissue-engineered cartilage in hydrodynamic cultivation with transient exposure to insulin-like grow th factor-1 and transforming growth factor- $\beta 1$. Tissue Eng Part A 19 : 2349-2360, 2013.

26. Davies LC, Blain EJ, Gilbert SJ, Caterson B and Duance VC: The potential of IGF-1 and TGFbetal for promoting 'adult' articular cartilage repair: An in vitro study. Tissue Eng Part A 14: 1251-1261, 2008.

27. Mizuta H, Sanyal A, Fukumoto T, Fitzsimmons JS, Matsui N, Bolander ME, Oursler MJ and O'Driscoll SW: The spatiotemporal expression of TGF-betal and its receptors during periosteal chondrogenesis in vitro. J Orthop Res 20: 562-574, 2002.

28. Inagaki M, Wang $\mathrm{Z}$ and Carr BI: Transforming growth factor beta 1 selectively increases gene expression of the serine/threonine kinase receptor 1 (SKR1) in human hepatoma cell lines. Cell Struct Funct 19: 305-313, 1994.
29. Nørgaard P, Spang-Thomsen M and Poulsen HS: Expression and autoregulation of transforming growth factor beta receptor mRNA in small-cell lung cancer cell lines. Br J Cancer 73: 1037-1043, 1996.

30. deMoura MD, Chamoun D, Resnick CE and Adashi EY: Insulin-like growth factor (IGF)-I stimulates IGF-I and type 1 IGF receptor expression in cultured rat granulosa cells: Autocrine regulation of the intrafollicular IGF-I system. Endocrine 13: 103-110, 2000

31. Barbara NP, Wrana JL and Letarte M: Endoglin is an accessory protein that interacts with the signaling receptor complex of multiple members of the transforming growth factor- $\beta$ superfamily. J Biol Chem 274: 584-594, 1999.

32. Longobardi L, O'Rear L, Aakula S, Johnstone B, Shimer K, Chytil A, Horton WA, Moses HL and Spagnoli A: Effect of IGF-I in the chondrogenesis of bone marrow mesenchymal stem cells in the presence or absence of TGF-beta signaling. J Bone Miner Res 21: 626-636, 2006.

33. Yaeger PC, Masi TL, de Ortiz JL, Binette F, Tubo R and McPherson JM: Synergistic action of transforming growth factor-beta and insulin-like growth factor-I induces expression of type II collagen and aggrecan genes in adult human articular chondrocytes. Exp Cell Res 237: 318-325, 1997.

34. Shakibaei M, John T, Rahmanzadeh R, Merker H (1999) Signal transduction by $\beta 1$ integrin receptors in human chondrocytes in vitro: Collaboration with the insulin-like growth factor-I receptor. Biochem J 342:615-623.

35. Landry J, Bernier D, Ouellet C, Goyette R and Marceau N: Spheroidal aggregate culture of rat liver cells: Histotypic reorganization, biomatrix deposition, and maintenance of functional activities. J Cell Biol 101: 914-923, 1985.

36. Anderer U and Libera J: In vitro engineering of human autogenous cartilage. J Bone Miner Res 17: 1420-1429, 2002.

37. Czech MP: Signal transmission by the insulin-like growth factors. Cell 59: 235-238, 1989.

38. Iwasa K, Hayashi S, Fujishiro T, Kanzaki N, Hashimoto S, Sakata S, Chinzei N, Nishiyama T, Kuroda R and Kurosaka M: PTEN regulates matrix synthesis in adult human chondrocytes under oxidative stress. J Orthop Res 32: 231-237, 2014.

39. Sakata S, Hayashi S, Fujishiro T, Kawakita K, Kanzaki N, Hashimoto S, Iwasa K, Chinzei N, Kihara S, Haneda M, et al: Oxidative stress-induced apoptosis and matrix loss of chondrocytes is inhibited by eicosapentaenoic acid. J Orthop Res 33: 359-365, 2015.

40. Bohensky J, Terkhorn SP, Freeman TA, Adams CS, Garcia JA, Shapiro IM and Srinivas V: Regulation of autophagy in cartilage: HIF-2 suppresses chondrocyte autophagy. Arthritis Rheum 60: 1406-1415, 2009

41. Babur BK, Ghanavi P,Levett P,Lott WB,Klein T,Cooper-White JJ, Crawford R and Doran MR: The interplay between chondrocyte redifferentiation pellet size and oxygen concentration. PLoS One 8: e58865, 2013. 